DOI: 10.12731/2227-930X-2017-1-65-77

\title{
ANALYTICAL AND SIMULATION PLANNING MODEL OF URBAN PASSENGER TRANSPORT
}

\section{Nikolaev A.B., Starikov V.S., Yagudaev G.G.}

The article described the structure of the analytical and simulation models to make informed decisions in the planning of urban passenger transport. Designed UML diagram that describes the relationship of classes of the proposed model. A description of the main agents of the model developed in the simulation AnyLogic. Designed user interface integration with GIS map. Also provides simulation results that allow concluding about her health and the possibility of its use in solving planning problems of urban passenger transport.

Keywords: simulation; traffic simulation; AnyLogic; urban public transport; passenger transportation; transport route; transport system.

\section{Introduction}

Now there is the problem of the movement of land transport in megacities. It appears, because there are different factors: different rate of passenger arrival, non-uniform loading of transport. [1]. Important tasks are to determine the number of units of rolling stock for passenger service and analyze the quality of passenger service [2].

To solve these problems, to effectively use tool of analytical and simulation modeling. In the general case, simulation can solve many problems: analyze and predict different situations, to adjust characteristics. Any simulation model can make a variety of experiments, even if it is impossible to realize them in reality $[3,12,13]$.

The actuality is that that before the project implementation, analytical and simulation modeling makes it easier to make decisions in the planning and management of urban passenger transport [16]. 


\section{The description of the objects for designing models}

In the task of planning urban passenger transport, there are the following objects: passengers, public transport, bus stops, transport fleet [14]. These objects have the following parameters: the estimated rate of arrival passengers, the number of transport, seating capacity, the interval of departure of transport. The result of solving the problem of planning of urban passenger transport by land, defines the routes and the headways of vehicles. We also consider the beginning and end time of traffic on a specified route, the actual number of available transport mean in the fleet. In addition, we consider the duration of the transport, which returned to the transport fleet after the working shift.

There is a sequence of bus stops for a specific route. The route has two directions: forward and reverse. The transport mean leaves from the fleet at regular intervals of time. It makes boarding and alighting of passengers at each bus stop. The rate of arrival passengers at bus stop depends on the time of day. All passengers out of the transport at bus stop before it moves to the fleet. Then transport mean going to the fleet without passenger.

\section{UML diagram project}

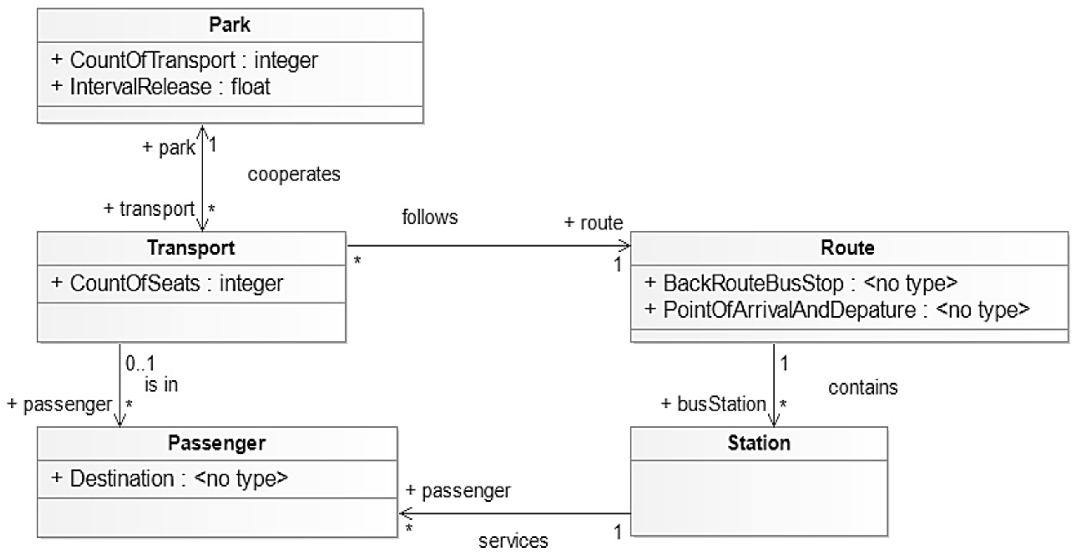

Fig. 1. UML Diagram 
We should to represent each object in a visual form. The most convenient and illustrative tool is view class diagrams (UML diagrams) [4-6].

In the following, a description of the function of each class show in Table 1.

Table 1.

Class description

\begin{tabular}{|c|l|}
\hline Class name & \multicolumn{1}{|c|}{ Summary } \\
\hline Park & $\begin{array}{l}\text { It simulates transport departure from the fleet and his arrival to him. } \\
\text { Interval departure means the period of time, when transport leaves } \\
\text { the park and begins work. }\end{array}$ \\
\hline Transport & $\begin{array}{l}\text { It is moving on the specified route. Transport serves passengers at } \\
\text { bus stops: boarding and alighting. }\end{array}$ \\
\hline Route & There is a sequence of stopping points \\
\hline Passenger & $\begin{array}{l}\text { It simulates awaiting the arrival of transport, boarding and alight- } \\
\text { ing from it. }\end{array}$ \\
\hline Station & $\begin{array}{l}\text { It is mean bus stop. Tfhis is the arrival of passengers, arrival and } \\
\text { departure of transport. }\end{array}$ \\
\hline
\end{tabular}

Figure 1 shows the class diagram. There is a connection between classes.

\section{Implementation Analytical and Simulation Model}

We use the software AnyLogic 7 to implement this task. AnyLogic is Multimethod Simulation Software, which supports many ways to create simulation models [7-8]:

- Discrete Event Simulation Modeling

- System Dynamic Simulation

- Agent Based Modeling.

This tool allows combining different methods.

In our case, we consider two methods to simulation: Agent Based Modeling and Discrete Event Simulation Modeling.

This model consists of different types of agents. We list them:

1. Park.

2. Passenger. 
3. Station. (It is mean bus stop).

4. Transport.

Each type of agent to do various functions. In addition to this model is the main module, which performs the simulation.

The Figure 2 shows the types of agents, implemented in the AnyLogic.

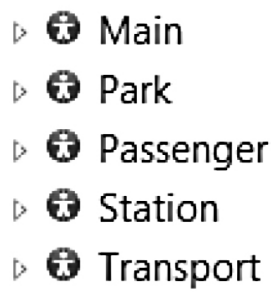

Fig. 2. Implemented agents

This article describes the types of agents that have peculiar properties for implementation [9-10].

\subsection{Agent "Park"}

The Figure 3 shows the elements that simulate the following processes: seize of resource and departure from the fleet, arrival to the fleet and release of resource. In this case, the resource is a transport.
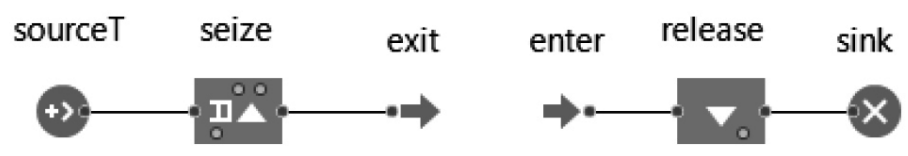

resourcePool

\section{५क}

Fig. 3. Elements for modeling work in the fleet

\subsection{Agent "Station"}

This type agent allows simulating bus stop. It can simulate the arrival of passengers to the waiting place. In addition, bus stop allows 
simulating the arrival of transport, the boarding and alighting of passengers.

There are also elements that simulate the various processes: arrival waiting passengers to the point, the arrival transport to the point, the boarding and alighting of passengers, departure passengers from point, the output of the transport from the point.

The Figure 4 shows the diagram elements.

\subsection{Agent "Transport"}

This type of agent simulates the traffic. He departures from the fleet and arrives to him, arrives at a bus stop and departure from it, makes boarding and alighting of passengers [17-19].

To simulate a composite process [20], we have developed the state diagram. The Figure 5 shows the state diagram.

The left is a diagram of the states of the operating mode of transport. The initial state is "work". It is a normal operating mode. When the working time comes to end, it goes into the state "goingToPark". This condition means that the transport should be follow to the park at the end of work.

On the right is a diagram of transport operation states. First, there are preparatory stages. After that, the cycle of actions begins. They are movements (go) and stops (stop). The cycle will continue until the transport will not follow the park (goToPark) after the stop.

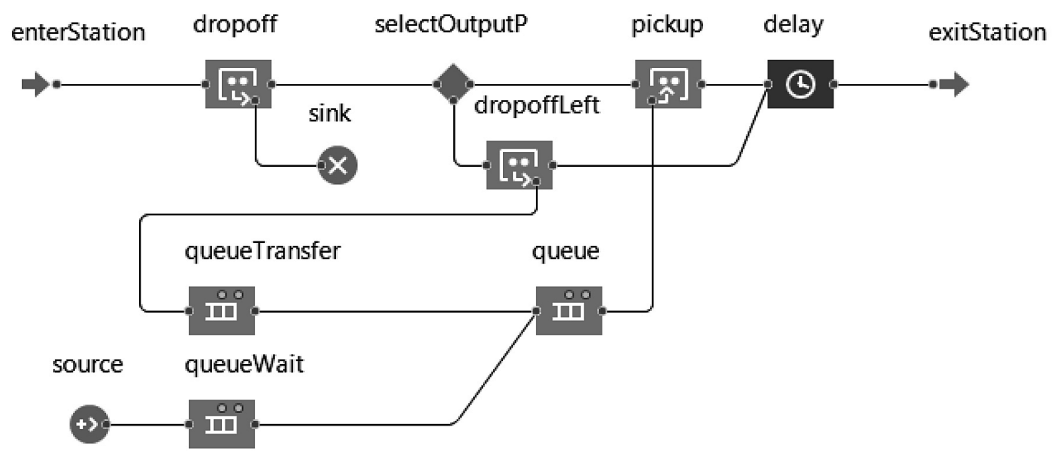

Fig. 4. Diagram elements for simulation of processes at bus stops 


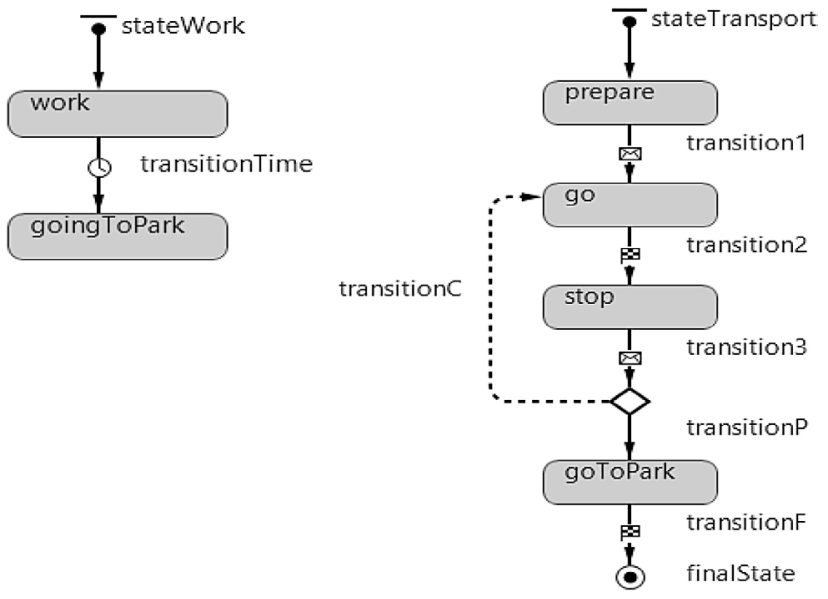

Fig. 5. State charts

\subsection{The implementation of the main model module}

The main module of the analytical-simulation model includes a set of objects. The main element that plays a big role is the GIS map. The Figure 6 shows an example of a GIS map. Many objects are associated with it: more information is available with its help. The main module performs general analytical and simulation modeling. With the GISmap [15], we can observe visual animation modeling - the operation process of transport, the location of the bus stop and the fleet.

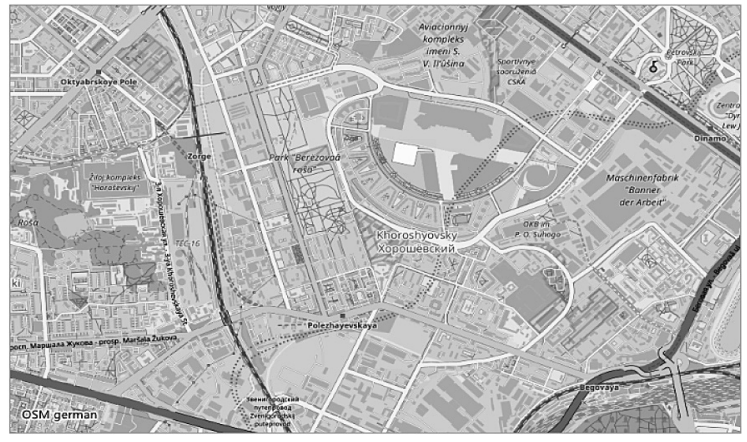

Fig. 6. GIS-map 


\section{Developing a user interface model}

After the development of the entire model, a user interface has been designed (Figure 7). Interface type is "Experiment". The initial data are the route, the rate of arrival of passengers, the coordinates of the fleet and the coordinates of the bus stops of the route, the number of transport means in the park, the working time, passenger capacity and the interval of departure from the park [11].

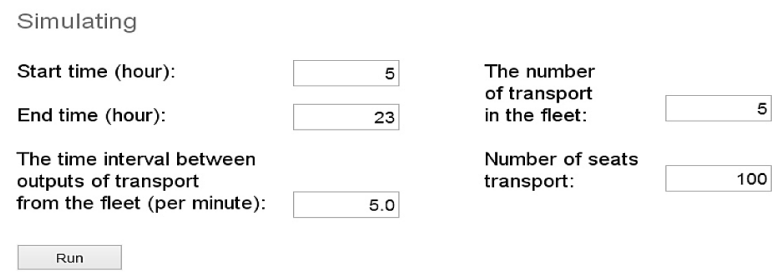

Fig. 7. Interface "Experiment"

The Figure 8 shows the results of visualizing the route on the GIS map. It shows the traffic along the specified route and various buses stop.

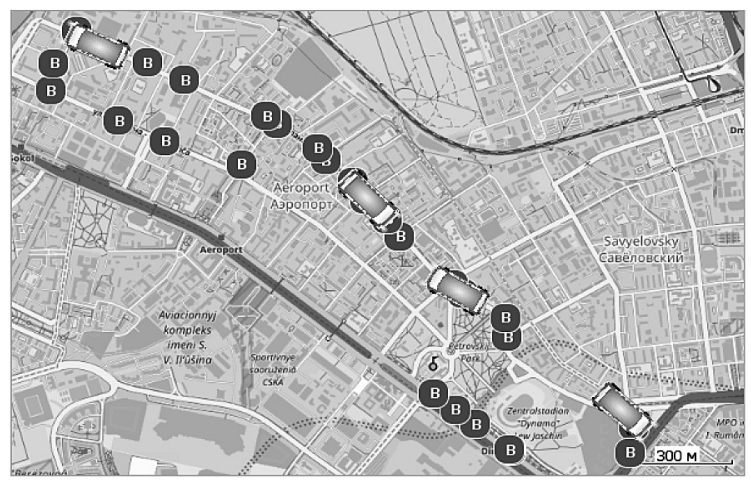

Fig. 8. Visualization of the route on the GIS-map

\section{Simulation results}

The developed model can to get various results. The Figure 9 shows the column diagrams of the number of waiting passengers at the buses stop at time. 
The Figure 10 shows the time plot of waiting passengers at the bus stop.

The Figure 11 shows the time plot of the number of filled seats in the transport mean.

Based on the analysis of the graphs presented in Figures 10-11, it can be assumed that for this route system is not overloaded, the traffic flow copes.

\section{Number of waiting passengers at public transport stops}

Forward direction

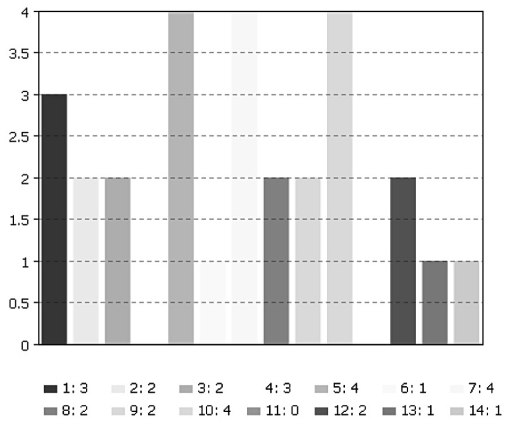

Reverse direction

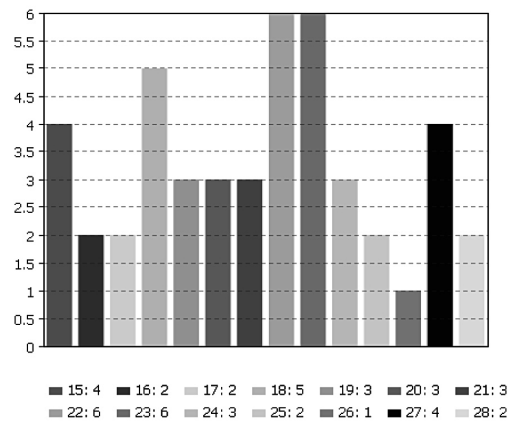

Fig. 9. The column diagrams

The time plot of the number of waiting passengers at public transport stops

\section{Forward direction}

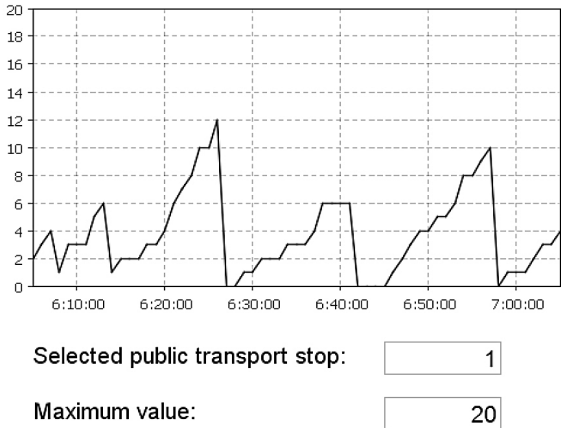

Fig. 10. Time plot of waiting passengers at the bus stop 
The time plot of the number of passengers in the transport

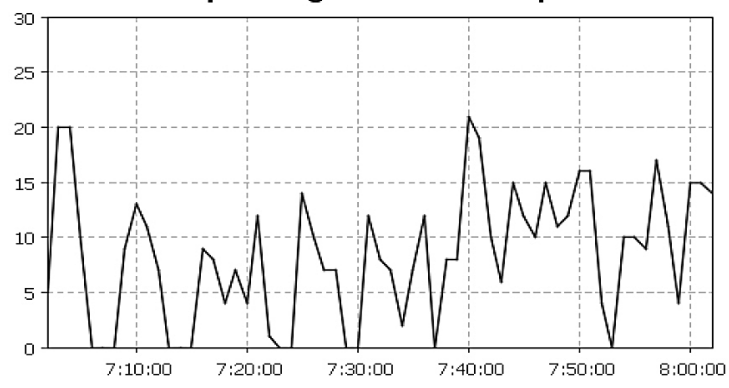

Selected transport:

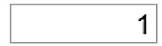

Maximum value:

30

Fig. 11. The time plot of the number of filled seats in the transport mean

We selectively analyze the detailed result of the simulation, i.e. during the whole simulation.

The Figure 12 is a simulated plot of the number of passengers in the transport during the whole simulation. Model time is given in hours.

The number of passengers in the transport

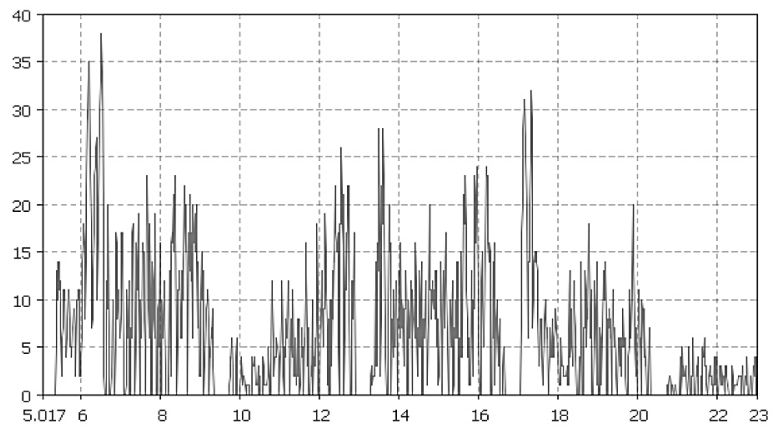

Selected transport: $3 \quad$ Selected hour:

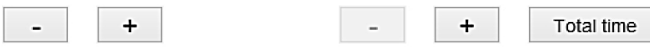

Fig. 12. Simulated plot of the number of passengers in the transport 
Based on the figure 12, we can assume that the capacity of the transport is sufficient. The transport system copes even in peak loads.

For the analysis of the average rate arrival of passengers Figures 13-14 show plots of waiting passengers at the buses stop. One of them in two directions is randomly selected.

The time plot of the number of waiting passengers at public transport stops

Forward direction

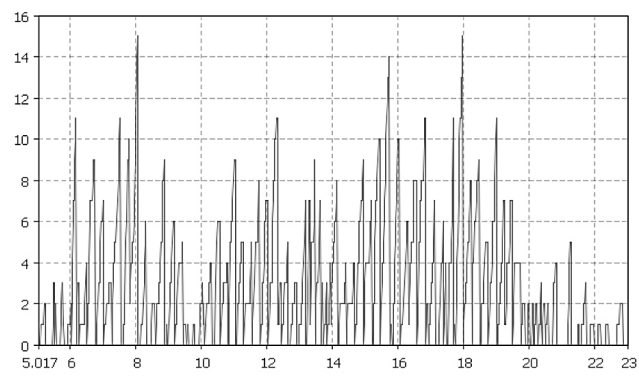

Selected public transport stop: 6 Selected hour:
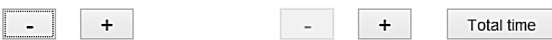

Fig. 13. Simulated plot of waiting passengers at the bus stop (forward direction)

The time plot of the number of waiting passengers at public transport stops

Reverse direction

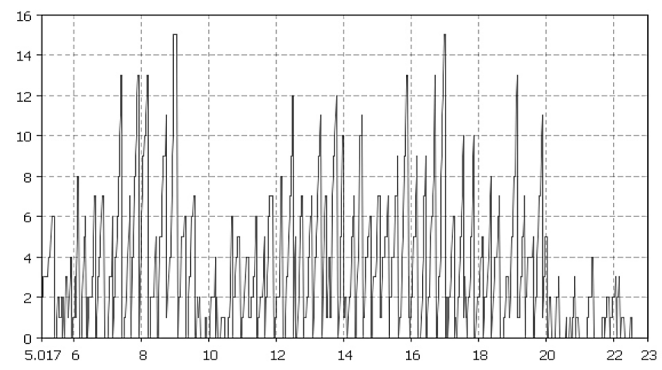

Selected public transport stop: 20 Selected hour:

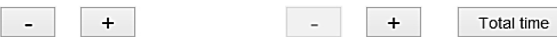

Fig. 14. Simulated plot of waiting passengers at the bus stop (reverse direction) 
Based on the result, it can be concluded that the transport has time to discuss passengers. The time interval in this case is acceptable.

The Figure 15 summarizes the results of simulated plots. It shows the average simulation result for the whole work.

The time plot of the number of waiting passengers

at public transport stops

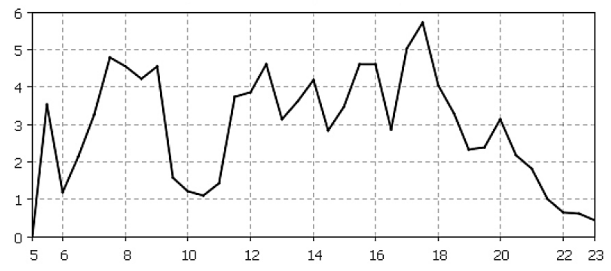

The time plot of the number of passengers in the transport

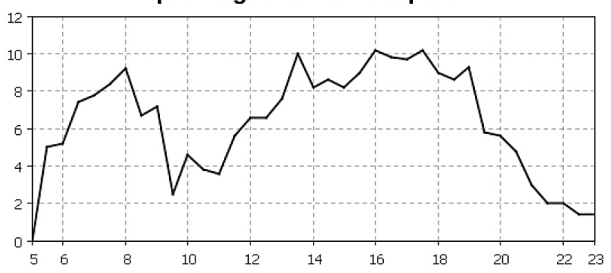

Fig. 15. General simulated plots

The simulation results for this route is seen that the plots are highly correlated with each other.

\section{Conclusions}

The article proposed and studied a model of surface passenger transport. It can be applied in research organisations, dealing with transport problems. Because of design, it is possible to solve some problems of traffic flow. Application AnyLogic 7 provides simulation modelling with GIS maps and get the necessary results.

\section{References}

1. Gorev A.E. Fundamentals of the theory of transport systems: proc. aid. SPb., 2010. 214 p. 
2. Spirin I.V. Organization and management of passenger road transport. M: Publishing center "Academy", 2014. 400 p.

3. Gasnikov A.V., etc. Introduction to mathematical modeling of traffic flows: textbook. Moscow, 2013.

4. UML Infrastructure Specification v 2.2.

5. Modelio Open Source Community. URL: www.modelio.org

6. The BPMN Specification.

7. URL: http://www.bpmn.org/

8. AnyLogic Simulation Software.

9. URL: www.anylogic.ru

10. Ilya Grigoryev. AnyLogic 7 in Three Days. Second Edition, 2015.

11. Ivanova G.S. software engineering: textbook. M.: KNORUS, 2011. $336 \mathrm{p}$.

12. The website about programming. URL: http://metanit.com/java/

13. Yakimov M.R. Transport planning: the creation of transport models of cities: monograph. M.: Logos, 2013. 188 p.

14. Nikolaev N.B., Sapego Y.S., Jakubovich A.N., Berner L.I., Ivakhnenko A.M. Simulation of Automatic Incidents Detection Algorithm on the Transport Network. International Journal of Environmental and Science Education. 2016, vol. 11, NO. 16, 9060-9078.

15. Nikolaev N.B., Sapego Y.S. Development of Traffic Accidents Control System. International Journal of Advanced Studies. N1, vol. 5. 2015.

16. Ismailov A.R., Nikolaev A.B. Transrelation Model and its applicability in the automatic control system of transport enterprises // Advanced management technologies in transport systems: collection of scientific works. Tr. MADI(GTU). M., 2006, pp. 50-53.

17. Ismailov A.R., Nikolaev A.B. Analysis of traffic flows by processing satellite navigation data // Advanced management technologies in transport systems: collection of scientific works. Tr. MADI(GTU). M., 2009, pp. 145-151.

18. Nikolaev A.B., Aleksakhin S.V., Kuznetsov I.A., Stroganov V.Y., Automated systems of information processing and management on motor transport: the Textbook for environments prof. education / Edited by A.B. Nikolaev. M.: Publishing house "Academy”, 2013. 224 p. 
19. Nikolaev A.B. Telematics in road transport / V.M. Vlasov, Jenkinsii S.V., Nikolaev A.B., Prikhodko V.M. M.: MADI, 2003. 173 p.

20. Vasyugova S.A., Nikolaev A.B. Hardware for automation control and industrial process control. A collection of "Automation and control in technical systems", № 1.1. 2014.

21. Vasyugova S.A., Nikolaev A.B. Concept of remote control systems of industrial robots. A collection of "Automation and control in technical systems", № 2.1. 2014.

22. Vasyugova S.A., Nikolaev A.B. Analysis of work of system of the help to the driver. Questions of modern technical science: new view and new decisions. The collection of scientific works following the results of the international scientific practical conference, No. 2. Yekaterinburg, 2015.

\section{DATA ABOUT THE AUTHORS}

Nikolaev Andrey Borisovich, Honoris Causa, Doctor of Technical Sciences, Professor, Head of Department

State Technical University - MADI

64, Leningradsky prospekt, Moscow, 125319, Russian Federation

nikolaev.madi@mail.ru

Starikov Vladislav Sergeevich, Master Student, Department of Automatized Control Systems

State Technical University - MADI

64, Leningradsky prospekt, Moscow, 125319, Russian Federation

Yagudaev Gennadiy Grigorievich, Doctor of Technical Sciences, Director

State Technical University - MADI, North Caucasian Branch 20, Industrial Str., Lermontov, Stavropol Region, 357340, Russian Federation

gena_yagudaev@mail.ru 